\title{
The Characterization of Linear Polyethylene SRM's 1482, 1483, and 1484. I. Introduction
}

\author{
Peter H. Verdier and Herman L. Wagner \\ Institute for Materials Research, National Bureau of Standards, Washington, D.C. 20234
}

(October 19, 1977)

\begin{abstract}
The National Bureau of Standards has issued a series of three linear polyethylene Standard Reference Materials, SRM 1482, 1483, and 1484. These polyethylenes have molecular weights of the order of 10,000 , 30,000 , and $100,000 \mathrm{~g} / \mathrm{mol}$, respectively, and ratios $M_{w} / M_{n}$ of weight- to number-average molecular weight of the order of 1.2. Their number-average molecular weights (by membrane osmometry), weight-average molecular weights (by light scattering), and limiting viscosity numbers in two solvents (by capillary viscometry) are certified; the procedures employed are described in subsequent papers in this series. In the present paper, we describe the preparation of the materials and some of their general properties.
\end{abstract}

Key words: Fraction; limiting viscosity number; narrow molecular weight distribution; number-average molecular weight; polyethylene; Standard Reference Material; weight-average molecular weight.

\section{Purpose}

The National Bureau of Standards has issued a series of three linear polyethylene Standard Reference Materials, SRM 1482, SRM 1483, and SRM 1484.* These polyethylenes have molecular weights of the order of $10,000,30,000$ and $100,000 \mathrm{~g} / \mathrm{mol}$, respectively, and ratios $M_{w} / M_{n}$ of weight- to number-average molecular weight of the order of 1.2. Their number-average molecular weights (by membrane osmometry), weight-average molecular weights (by light scattering), and limiting viscosity numbers in two solvents (by capillary viscometry) are certified; the certificates are reproduced at the end of this paper. They are intended for the calibration and checking of instruments used in polymer technology and science for the determination of properties related to molecular weight and distribution in molecular weight, such as light scattering photometers and gel permeation chromatographs. They should also prove useful as characterized samples for measurements of other physical properties of linear polyethylene.

Succeeding papers of this series describe the experimental methods and data analysis techniques employed to obtain the certificate values of number-average molecular weight [la], ${ }^{1}$ weight-average molecular weight [1b], and limiting viscosity number [1c] of SRM's 1482, 1483, and 1484. In the present paper, we describe the preparation and treatment of these materials, and the results of various semiquantitative measurements employed to estimate such uncertified properties as distribution in molecular weight, impurity content, etc.

\section{Description of Materials}

Standard Reference Materials 1482, 1483, and 1484 were prepared from fractions produced by Waters Associates,

* Available through the Office of Standard Reference Materials, National Bureau of Standards, Washington, D. C. 20234 .

${ }^{1}$ Figures in brackets indicate literature references at the end of this paper.
Inc., Milford, Mass. ${ }^{2}$ by large-scale gel permeation fractionation of a linear polyethylene from the same stock as Standard Reference Material 1475 (Linear Polyethylene Whole Polymer),* and with physical properties essentially identical with those of SRM 1475. As reported elsewhere [2, 3], SRM 1475 has a degree of branching undetectable by infrared spectroscopy and limiting viscosity number, and an ash content of 0.002 percent. We believe that the fractions will have the same characteristics. In other respects, however, the three fractions have different histories and are discussed separately in the following sections. Gel permeation chromatography of all three Standard Reference Materials shows a single symmetrical peak, without noticeable shoulders and of a width consistent with a ratio $M_{w} / M_{n}$ of weight- to number-average molecular weight, estimated as described elsewhere [2], of the order of 1.2 .

\subsection{SRM 1483}

According to the producer, the material for SRM 1483 was made by blending and reprecipitation (from xylene by cooling) of about 600 nine-gram "cuts" obtained by gel permeation fractionation, in Styragel columns, of the parent material in xylene with antioxidant at $135^{\circ} \mathrm{C}$. After the final reprecipitation, the material was washed with acetone and air-dried. Upon delivery to the National Bureau of Standards, the entire stock (about $5.5 \mathrm{~kg}$ ) was blended in a two-cone porcelainlined mixer, packed in 46 quart jars and stored under dry nitrogen at reduced pressure.

As a check on homogeneity, two samples were taken from each of five jars chosen at random. Viscosity numbers at five concentrations in 1,2,4-trichlorobenzene were determined as described elsewhere [lc] for each sample. The results showed no statistically significant variation within jars or between jars.

${ }^{2}$ Certain commercial equipment, instruments, or materials are identified in this paper in order to specify the experimental procedure. In no case does such identification imply recommendation or endorsement by the National Bureau of Standards, nor does it imply that the material or equipmen identified is necessarily the best available for the purpose. 
Trace-metal analyses (by emission spectroscopy on $1 / 2 \mathrm{~g}$ samples) showed iron and magnesium not exceeding $1 \mathrm{ppm}$. Total volatiles detected by mass spectrometry upon heating the material to $300{ }^{\circ} \mathrm{C}$ did not exceed 0.1 percent. Carbonhydrogen analyses agreed with the values expected for $\left(\mathrm{CH}_{2}\right)_{n}$ to within 0.1 percent.

\subsection{SRM 1482}

The gel permeation fractionations which produced the material for SRM 1483 as described above also yielded "cuts" at higher and lower molecular weights. Five batches of the lower molecular weight materials were found to be suitable for a Standard Reference Material with a molecular weight of the order of 10,000 . The batches ranged in weight from 100 to $400 \mathrm{~g}$ each. Their $M_{w} / M_{n}$ ratios, estimated by gel permeation chromatography, were in the range 1.1 to 1.2. The batches were individually reprecipitated as described below, then blended to make the final product.

Reprecipitation was carried out in 1,2,4-trichlorobenzene containing 500 ppm of an antioxidant, 2,6-di-tert-butyl-4methylphenol. For each batch, sufficient solvent to make a solution of concentration $0.5-1$ percent (by weight) was first heated to $130{ }^{\circ} \mathrm{C}$ under nitrogen, and the polyethylene added to the hot solvent while stirring. The material dissolved in 5-10 min. The solution was allowed to cool, over a period of several hours, to $45-65{ }^{\circ} \mathrm{C}$ with gentle stirring. During the cooling the polyethylene precipitated, forming a floating slurry, and the bulk of the liquid phase was pumped out.

The individual slurries were blended by mixing and vigorous stirring for $1 / 2-1 \mathrm{hr}$. The blended slurry was strained through a 40 mesh screen, filtered on filter paper, and washed three times with acetone. It was then air-dried at room temperature until the acetone content was about 10 percent by weight, dried in a vacuum oven for $13 \mathrm{hrs}$ at $50{ }^{\circ} \mathrm{C}$, and bottled under dry nitrogen at reduced pressure.

Residual 1,2,4-trichlorobenzene content was estimated spectrophotometrically. Four samples of SRM 1482 were dissolved in cyclohexane (at $140{ }^{\circ} \mathrm{C}$ under pressure) to give solutions with concentrations from 30 to $160 \mathrm{~g} / \mathrm{L}$. The polyethylene was then reprecipitated by cooling to room temperature and removed by filtration. The concentration of 1,2,4-trichlorobenzene in the filtrate was estimated by comparing its optical density at a wavelength of $286 \mathrm{~nm}$ with that of solutions of known amounts of 1,2,4-trichlorobenzene in cyclohexane. The 1,2,4-trichlorobenzene content estimated by this method was $0.053,0.058,0.059$, and 0.065 percent for the four samples. Based on these values, we estimate an upper limit of 0.1 percent residual 1,2,4-trichlorobenzene in SRM 1482.

Total volatile content was estimated by measuring the weight lost by three $0.5 \mathrm{~g}$ samples and a blank after heating to $50{ }^{\circ} \mathrm{C}$ for one $\mathrm{h}$ at a pressure of about $10 \mathrm{~Pa}$. During this period, the blank decreased in weight by $0.1 \mathrm{mg}$, and the samples decreased by $0.2,0.3$, and $0.4 \mathrm{mg}$. No further weight loss was observed in either blank or samples after $2^{1 / 2}$ additional hours of drying under the same conditions. Based on these values, we estimate total volatiles in this material to be 0.1 percent or less.

\subsection{SRM 1484}

Six batches of the polyethylene "cuts" described in the preceding section were chosen as starting materials for SRM 1484. The batches consisted of 100 to $300 \mathrm{~g}$ each. Their gel permeation chromatograms showed major peaks at molecular weights in the vicinity of 100,000 , with ratios $M_{w} / M_{n}$ in the range $1.1-1.2$, and minor peaks, amounting to a few percent of the total material, in the molecular-weight range 6003600 . In order to remove the low molecular-weight components, the individual batches were fractionally reprecipitated as described below.

Fractional reprecipitations were carried out in 1,2,4-trichlorobenzene containing 500 ppm 2,6-di-tert-butyl-4-methylphenol. The solvent was preheated and the solutions prepared as described above for SRM 1482, except that the higher molecular-weight material required $1 / 2$ to $1 \mathrm{~h}$ to dissolve. The hot solution was then cooled under nitrogen at a rate of $5-6{ }^{\circ} \mathrm{C} / \mathrm{h}$ to $80{ }^{\circ} \mathrm{C}$ with gentle stirring. During the cooling, most of the higher molecular-weight components precipitated, forming a slurry. The stirring and the nitrogen cover were then discontinued, and the system was left unstirred at $80{ }^{\circ} \mathrm{C}$ until the precipitate had all floated to the surface of the liquid. The underlying liquid, containing the low molecular-weight contaminant, was pumped out. Fresh 1,2,4-trichlorobenzene preheated to $82-85{ }^{\circ} \mathrm{C}$ was added, and the precipitate was washed by stirring under nitrogen for several minutes, then left unstirred for a minimum of $3 \mathrm{~h}$ at $80{ }^{\circ} \mathrm{C}$. The liquid underlying the precipitate was again pumped out and the remaining slurry cooled to room temperature. Gel permeation chromatograms of the resulting precipitates showed no sign of the low molecular-weight contaminant.

The individual slurries were blended by mixing and vigorous stirring for two hours. The blended slurry was filtered on filter paper and washed three times with ethanol and once with acetone. It was then air-dried at room temperature for a week, further dried in a vacuum oven at 50 ${ }^{\circ} \mathrm{C}$ for $8 \mathrm{~h}$, and bottled under dry nitrogen at reduced pressure.

Residual 1,2,4-trichlorobenzene content of SRM 1484 was estimated spectrophotometrically by the method described in section 2.2 for SRM 1482. Measurements on two solutions, of initial SRM 1484 concentrations about $100 \mathrm{~g} / \mathrm{L}$, yielded estimates of 1,2,4-trichlorobenzene content of 0.057 and 0.063 percent. From these values, we estimate an upper limit of 0.1 percent residual 1,2,4-trichlorobenzene in SRM 1484.

Total volatile content was estimated by measuring the weight lost by four $0.5 \mathrm{~g}$ samples and two blanks after heating to $60^{\circ} \mathrm{C}$ for $2 \mathrm{~h}$ at a pressure of $10-100 \mathrm{~Pa}$. During this period, the blanks decreased in weight by 0.03 and 0.07 $\mathrm{mg}$, and the samples decreased by $0.11,0.11,0.13$, and $0.14 \mathrm{mg}$. No further weight loss was observed in either blank or samples after $2 \frac{1}{2}$ additional hours of drying under the same conditions. These values appear to imply a volatile content of about 0.02 percent, which is inconsistent with the observed residual 1,2,4-trichlorobenzene content. We conclude that the drying procedure employed was incapable of removing all the residual 1,2,4-trichlorobenzene. As a result of the fractional reprecipitation of SRM 1484, we believe that 1,2,4-trichlorobenzene is the only likely volatile contami- 
nant, and that our estimated upper limit of 0.1 percent residual 1,2,4-trichlorobenzene is also a safe upper limit for total volatiles in SRM 1484.

Note: The word liter is abbreviated lowercase "l" in these Certificates. The approved abbreviation for liter is capital "L".

\section{References}

[1] The Characterization of Linear Polyethylene SRM's 1482, 1483, and 1484:

(a) Wagner, H. L., and Verdier, P. H., II. Number-Average Molecular Weights by Membrane Osmometry, J. Res. Nat Bur. Stand, (U.S.) 83, No. 2 (Mar.-Apr. 1978). (b) Han, C. C., Verdier, P. H., and Wagner, H. L., III. WeightAverage Molecular Weights by Light Scattering, J. Res. Nat. Bur. Stand. (U.S.) 83, No. 2 (Mar.-Apr. 1978).

(c) Wagner, H. L., and Verdier, P. H., IV. Limiting Viscosity Numbers by Capillary Viscometry, J. Res. Nat. Bur. Stand. (U.S.) 83, No. 2 (Mar.-Apr. 1978)

[2] Hoeve, C. A. J., et al., The Characterization of Linear Polyethylene SRM 1475 (a series of ten papers), J. Res. Nat. Bur. Stand. (U.S. 76A, No. 2, 137-170 (Mar.-Apr. 1972); also available as Wagner, H. L., and Verdier, P. H. Eds., The Characterization of Linear Polyethylene SRM 1475, Nat. Bur. Stand. (U.S.). Spec. Publ 260-42, 39 pages (Sept. 1972).

[3] Wagner, H. L. and Hoeve, C. A. J., The Mark-Houwink Equation and Chain Dimensions of Linear Polyethylene in Theta Solvents, J. Polym. Sci., Symposium No. 54, 327-339 (1976). 
U.S. Department of Commerce

Elliot L. Richardson,

Secretary

National Bureau of Standards

Ernest Ambler, Acting Director

\section{National Rarean of Standartz Urertificate Standard Reference Material 1482 Linear Polyethylene
(Narrow Molecular Weight Distribution)}

P. H. Verdier and H. L. Wagner

This Standard Reference Material is intended for the calibration and checking of instruments used in polymer technology and science for the determination of molecular weight and molecular weight distribution, and for use as a characterized sample for measurements of other physical properties of linear polyethylene.

\begin{tabular}{|l|c|c|c|c|}
\hline \multicolumn{1}{|c|}{ Property } & Value & $\begin{array}{c}\text { Sample standard } \\
\text { deviation of } \\
\text { value, percent }\end{array}$ & $\begin{array}{c}\text { Number of } \\
\text { degrees of } \\
\text { freedom }\end{array}$ & $\begin{array}{c}\text { Expected limit of } \\
\text { systematic error, } \\
\text { percent }\end{array}$ \\
\hline $\begin{array}{l}\text { Number-average } \\
\text { molecular weight, } \\
\mathrm{M}_{\mathrm{n}}, \mathrm{g} / \mathrm{mol}^{\mathrm{a}} \\
\text { Weight-average } \\
\text { molecular weight, } \\
\mathrm{M}_{\mathrm{w}}, \mathrm{g} / \mathrm{mol}^{\mathrm{c}}\end{array}$ & 11,400 & 0.7 & 18 & $2^{\mathrm{b}}$ \\
$\begin{array}{l}\text { Limiting viscosity } \\
\text { number, ml/g: } \\
\text { at } 130^{\circ} \mathrm{C} \text { in } \\
1,2,4 \text {-trichloro- } \\
\text { benzene }\end{array}$ & 13,600 & 1.0 & 6 & $11^{\mathrm{b}, \mathrm{d}}$ \\
$\begin{array}{l}\text { at } 130^{\circ} \mathrm{C} \text { in } \\
1 \text {-chloro- } \\
\text { naphthalene }\end{array}$ & 40.2 & 0.33 & 28 & 1 \\
\hline
\end{tabular}

a. Determined by membrane osmometry in 1-chloronaphthalene at $126^{\circ} \mathrm{C}$.

b. The expected limits of systematic error for the number- and weight-average molecular weights are based on analyses of the osmometry and light-scattering determinations, respectively, without taking account of the necessity of $\mathbf{M}_{\kappa}$ exceeding $\mathbf{M}_{n}$.

c. Determined by light scattering in 1-chloronaphthalene at $135^{\circ} \mathrm{C}$ based on a value of $17.8 \times 10^{-6} \mathrm{~cm}^{-1}$ for the Rayleigh ratio for the vertically polarized scattering of vertically polarized light, of wavelength $546 \mathrm{~nm}$ in vacuum. from benzene at $23^{\circ} \mathrm{C}$. This value was derived from published values of the unpolarized Rayleigh ratio and the depolarization ratio for unpolarized light [D. J. Coumou. J. Colloid Sci. 15, $408(1960)$ ]. The differential refractive index of this polyethylene in 1-chloronaphthalene at $135^{\circ} \mathrm{C}$. also required for the calculation of molecular weight, was found to be $-0.195 \mathrm{ml} \mathrm{g}$ at wavelength $546 \mathrm{~nm}$ in vacuum. based on the value of 0.1429 $\mathrm{ml} / \mathrm{g}$ for the differential refractive index of sucrose in aqueous solution at $25^{\circ} \mathrm{C}$ [Norberg and Sundelöf, Makromol. Chem. 77,77 (1964) ]

d. The expected limit of systematic error from all sources except the vertically polarized Rayleigh ratio for benzene is 4 percent.

Measurements leading to the certification of this Standard Reference Material were performed by J. E. Brown, R. G. Christensen, C. C. Han, J. R. Maurey, P. H. Verdier and H. L. Wagner in the Polymers Division, Institute for Materials Research.

Washington, D.C. 20234

October 18, 1976
J. Paul Cali, Chief

Office of Standard Reference Materials 
This sample of linear polyethylene was prepared by recrystallization from 1,2,4-trichlorobenzene and subsequent blending of fractions produced by Waters Associates, Inc. of Milford, Mass., by large-scale gel permeation chromatography, from a linear polyethylene substantially identical with Standard Reference Material 1475 (Linear Polyethylene, Whole Polymer). Both total volatiles, estimated gravimetrically, and residual 1,2,4-trichlorobenzene content, estimated spectrophotometrically, do not exceed 0.1 percent.

The maximum rate of shear in the Ubbelohde capillary viscometers employed for the determination of limiting viscosity numbers was $3000 \mathrm{sec}^{-1}$ for 1,2,4-trichlorobenzene and $2000 \mathrm{sec}^{-1}$ for 1-chloronaphthalene. The maximum specific viscosities were 0.4 in both solvents.

A report describing the investigations required for this and related polyethylene Standard Reference Materials will be published as an NBS Special Publication. 
U.S. Department of Commerce

Elliot L. Richardson,

Secretary

National Bureau of Standards Ernest Ambler, Acting Director

\title{
Watianal 解ureau of Stantard (Uiertificate Standard Reference Material 1483 Linear Polyethylene (Narrow Molecular Weight Distribution)
}

\author{
H. L. Wagner and P. H. Verdier
}

This Standard Reference Material is intended for the calibration and checking of instruments used in polymer technology and science for the determination of molecular weight and molecular weight distribution, and for use as a characterized sample for measurements of other physical properties of linear polyethylene.

\begin{tabular}{|c|c|c|c|c|}
\hline Property & Value & $\begin{array}{l}\text { Sample standard } \\
\text { deviation of } \\
\text { value, percent }\end{array}$ & $\begin{array}{c}\text { Number of } \\
\text { degrees of } \\
\text { freedom }\end{array}$ & $\begin{array}{c}\text { Expected limit of } \\
\text { systematic error, } \\
\text { percent }\end{array}$ \\
\hline $\begin{array}{l}\text { Number-average } \\
\text { molecular weight, } \\
\mathrm{M}_{\mathrm{n}}, \mathrm{g} / \mathrm{mol}^{\mathrm{a}}\end{array}$ & 28,900 & 1.5 & 22 & $2^{\mathrm{b}}$ \\
\hline $\begin{array}{l}\text { Weight-average } \\
\text { molecular weight, } \\
\mathbf{M}_{\mathrm{w}}, \mathrm{g} / \mathrm{mol}^{\mathrm{c}}\end{array}$ & 32,100 & 2.3 & 4 & $11^{\mathrm{b}, \mathrm{d}}$ \\
\hline $\begin{array}{l}\text { Limiting viscosity } \\
\text { number, } \mathrm{ml} / \mathrm{g} \text { : }\end{array}$ & & & & \\
\hline $\begin{array}{l}\text { at } 130^{\circ} \mathrm{C} \text { in } \\
1,2,4 \text {-trichloro- } \\
\text { benzene }\end{array}$ & 79.4 & 0.39 & 24 & 1 \\
\hline $\begin{array}{l}\text { at } 130^{\circ} \mathrm{C} \text { in } \\
\text { 1-chloro- } \\
\text { naphthalene }\end{array}$ & 70.6 & 0.39 & 17 & 1 \\
\hline
\end{tabular}

a. Determined by membrane osmometry in 1-chloronaphthalene at $129^{\circ} \mathrm{C}$

b. The expected limits of systematic error for the number-and weight-average molecular weights are based on analyses of the osmometry and light-scattering determinations, respectively, without taking account of the recessity of $\mathbf{M}_{u}$ exceeding $\mathbf{M}_{n}$.

c. Determined by light scattering in 1-chloronaphthalene at $135^{\circ} \mathrm{C}$ based on a value of $17.8 \times 10^{-6} \mathrm{~cm}^{-1}$ for the Rayleigh ratio for the vertically polarized scattering of vertically polarized light, of wavelength $546 \mathrm{~nm}$ in vacuum, from benzene at $23{ }^{\circ} \mathrm{C}$. This value was derived from published values of the unpolarized Rayleigh ratio and the depolarization ratio for unpolarized light [D. J. Coumou, J. Colloid Sci. 15, $408(1960)$ ]. The differential refractive index of this polyethylene in 1-chloronaphthalene at $135^{\circ} \mathrm{C}$, also required for the calculation of molecular weight, was found to be $-0.193 \mathrm{ml} / \mathrm{g}$ at wavelength $546 \mathrm{~nm}$ in vacuum, based on the value of 0.1429 $\mathrm{ml} / \mathrm{g}$ for the differential refractive index of sucrose in aqueous solution at $25^{\circ} \mathrm{C}$ [Norberg and Sundelö, Makromol. Chem. 77,77 (1964) ]

d. The expected limit of systematic error from all sources except the vertically polarized Rayleigh ratio for benzene is 4 percent

Measurements leading to the certification of this Standard Reference Material were performed by J. E. Brown, R. G. Christensen, J. R. Maurey and H. L. Wagner in the Polymers Division, Institute for Materials Research.

Washington, D.C. 20234

March 9, 1976
J. Paul Cali, Chief

Office of Standard Reference Materials 
This sample of linear polyethylene was prepared by Waters Associates, Inc. of Milford, Mass., by large-scale gel permeation chromatography, from a linear polyethylene substantially identical with Standard Reference Material 1475 (Linear Polyethylene, Whole Polymer). Volatiles detected by mass spectrometric analysis upon heating the material to $300^{\circ} \mathrm{C}$ did not exceed 0.1 percent. Viscosity numbers of samples chosen at random from different parts of the material showed no statistically significant sample-to-sample variation.

The maximum rate of shear in the Ubbelohde capillary viscometer employed for the determination of limiting viscosity numbers was $3000 \mathrm{sec}^{-1}$ for 1,2,4-trichlorobenzene and $2000 \mathrm{sec}^{-1}$ for 1-chloronaphthalene. The maximum specific viscosities were 0.4 in both solvents.

A report describing the investigations required for this and related polyethylene Standard Reference Materials will be published as an NBS Special Publication. 
U.S. Department of Commerce

Elliot L. Richardson,

Secretary

National Bureau of Standards Ernest Ambler, Acting Director

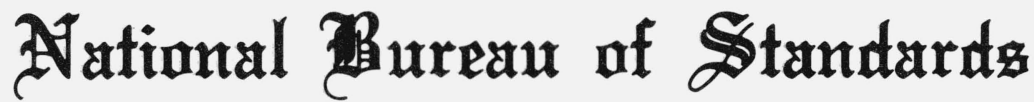 $\mathbb{U}_{\text {ertificate }}$ Standard Reference Material 1484 Linear Polyethylene (Narrow Molecular Weight Distribution)}

P. H. Verdier and H. L. Wagner

This Standard Reference Material is intended for the calibration and checking of instruments used in polymer technology and science for the determination of molecular weight and molecular weight distribution, and for use as a characterized sample for measurements of other physical properties of linear polyethylene.

\begin{tabular}{|c|c|c|c|c|}
\hline Property & Value & $\begin{array}{c}\text { Sample standard } \\
\text { deviation of } \\
\text { value, percent }\end{array}$ & $\begin{array}{c}\text { Number of } \\
\text { degrees of } \\
\text { freedom }\end{array}$ & $\begin{array}{c}\text { Expected limit of } \\
\text { systematic error, } \\
\text { percent }\end{array}$ \\
\hline $\begin{array}{l}\text { Number-average } \\
\text { molecular weight, } \\
\mathrm{M}_{\mathrm{n}}, \mathrm{g} / \mathrm{mol}^{\mathrm{a}}\end{array}$ & 100,500 & 3.7 & 34 & $4^{b}$ \\
\hline $\begin{array}{l}\text { Weight-average } \\
\text { molecular weight, } \\
\mathrm{M}_{\mathrm{w}}, \mathrm{g} / \mathrm{mol}^{\mathrm{c}}\end{array}$ & 119,600 & 1.8 & 5 & $11^{\mathrm{b}, \mathrm{d}}$ \\
\hline $\begin{array}{l}\text { Limiting viscosity } \\
\text { number, } \mathrm{ml} / \mathrm{g} \text { : }\end{array}$ & & & & \\
\hline $\begin{array}{l}\text { at } 130^{\circ} \mathrm{C} \text { in } \\
1,2,4 \text {-trichloro- } \\
\text { benzene }\end{array}$ & 197.9 & 0.30 & 22 & 1 \\
\hline $\begin{array}{l}\text { at } 130^{\circ} \mathrm{C} \text { in } \\
\text { 1-chloro- } \\
\text { naphthalene }\end{array}$ & 169.4 & 0.35 & 22 & 1 \\
\hline
\end{tabular}

a. Determined by membrane osmometry in 1-chloronaphthalene at $130^{\circ} \mathrm{C}$.

b. The expected limits of systematic error for the number-and weight-average molecular weights are based on analyses of the osmometry and light-scattering determinations, respectively, without taking account of the necessity of $M_{w}$ exceeding $M_{n}$.

c. Determined by light scattering in 1-chloronaphthalene at $135^{\circ} \mathrm{C}$ based on a value of $17.8 \times 10^{-6} \mathrm{~cm}^{-1}$ for the Rayleigh ratio for the vertically polarized scattering of vertically polarized light, of wavelength $546 \mathrm{~nm}$ in vacuum, from benzene at $23^{\circ} \mathrm{C}$. This value was derived from published values of the unpolarized Rayleigh ratio and the depolarization ratio for unpolarized light [D. J. Coumou, J. Colloid Sci. 15, $408(1960)$ ]. The differential refractive index of this polyethylene in 1-chloronaphthalene at $135^{\circ} \mathrm{C}$, also required for the calculation of molecular weight, was found to be $-0.191 \mathrm{ml} / \mathrm{g}$ at wavelength $546 \mathrm{~nm}$ in vacuum, based on the value of 0.1429 $\mathrm{ml} / \mathrm{g}$ for the differential refractive index of sucrose in aqueous solution at $25^{\circ} \mathrm{C}$ [Norberg and Sundelöf, Makromol. Chem. 77, 77 (1964) ].

d. The expected limit of systematic error from all sources except the vertically polarized Rayleigh ratio for benzene is 4 percent.

Measurements leading to the certification of this Standard Reference Material were performed by J. E. Brown, R. G. Christensen, C. C. Han, J. R. Maurey, P. H. Verdier and H. L. Wagner in the Polymers Division, Institute for Materials Research.

Washington, D.C. 20234

October 18, 1976
J. Paul Cali, Chief

Office of Standard Reference Materials 
This sample of linear polyethylene was prepared by fractional recrystallization from 1,2,4-trichlorobenzene and subsequent blending of fractions produced by Waters Associates, Inc. of Milford, Mass., by large-scale gel permeation chromatography, from a linear polyethylene substantially identical with Standard Reference Material 1475 (Linear Polyethylene, Whole Polymer). The fractions as received contained several percent by weight of polyethylene components with molecular weights in the range 1,000-4,000. The amount of this material remaining after the fractional recrystallization is less than 0.5 percent. Both total volatiles, estimated gravimetrically, and residual 1,2,4-trichlorobenzene content, estimated spectrophotometrically, do not exceed 0.1 percent.

The maximum rate of shear in the Ubbelohde capillary viscometers employed for the determination of limiting viscosity numbers was $3,000 \mathrm{sec}^{-1}$ for 1,2,4-trichlorobenzene and $2,000 \mathrm{sec}^{-1}$ for 1-chloronaphthalene. The maximum specific viscosities were 0.4 in both solvents.

A report describing the investigations required for this and related polyethylene Standard Reference Materials will be published as an NBS Special Publication. 